\title{
ÁMBITO MATERIAL DEL REGLAMENTO BRUSELAS I BIS, PRÁCTICAS COMERCIALES DESLEALES (B2C) Y ACCIONES COLECTIVAS DE CESACIÓN: COMENTARIO A LA STJUE MOVIC BV (C-73/19)
}

\author{
MATERIAL SCOPE OF BRUSSELS I BIS REGULATION, UNFAIR \\ COMMERCIAL PRACTICES (B2C) AND INJUNCTIONS TO \\ PROTECT COLLECTIVE CONSUMERS INTERESTS: CJEU \\ JUDGMENT MOVIC BV (C-73/19)
}

\author{
Anna María Ruiz Martín \\ Lecturer in Law (GBS-UOC) \\ Abogada del ICAM
}

\begin{abstract}
Recibido: 15.11.2020 / Aceptado: 14.12.2020
DOI: https://doi.org/10.20318/cdt.2021.6016
\end{abstract}

\begin{abstract}
Resumen: La STJUE Movic BV contiene cuestiones relativas al Derecho internacional privado europeo (DIPr) y al Derecho derivado de prácticas comerciales desleales y de consumo de la UE. Uno de sus aspectos más interesantes es la interpretación del concepto europeo de "materia civil y mercantil" del Reglamento Bruselas I bis. Un concepto que lejos de ser pacífico ha generado numerosas cuestiones de tipo prejudicial al Tribunal de Justicia de la Unión Europea por parte de tribunales y autoridades de los Estados miembros desde los orígenes de este (i.e.: Convenio de Bruselas de 1968) en todos instrumentos del DIPr patrimonial europeo. La materia objeto del litigio depende de ser caracterizada como materia "civil y mercantil" para entender que tiene cabida en el ámbito material del Reglamento Bruselas I bis. Para ello, los tribunales tienen que considerar dos elementos clave que el TJUE ha ofrecido en esta jurisprudencia sobre el concepto "materia civil y mercantil" y que en este asunto, se vuelven a traer a colación.

De otra parte, en relación con el Derecho derivado de consumo, siendo parte de su contenido la regulación de las prácticas comerciales desleales contra los consumidores, el asunto Movic BV, también se hace eco de aspectos controvertidos cómo son es la naturaleza de las acciones transfronterizas de cesación atendiendo al complejo entramado y relación de normas de este acquis communautaire.

Palabras clave: materia "civil y mercantil"; prácticas comerciales desleales; prácticas de mercado; Business to consumer (B2C); Reglamento Bruselas I bis; locus standi; iure imperii; acciones de cesación; multas coercitivas; asociaciones de consumidores; intereses colectivos; autoridad; Directiva 29/2005; Directiva 22/2009

\footnotetext{
Abstract: Movic $B V$ case before the CJEU is a quite interesting preliminary ruling with regard to the European Private international law (EPIL) as well as to the unfair commercial practices and consumer law of the EU substantive law on the subject. One of the most remarkable aspects concerning the EPIL is the analysis that the CJEU made of the far from being pacific autonomous concept, - "civil and commercial matters"-, of the Brussels I bis Regulation. An autonomous concept which has generated since the origin of the Brussels I bis regulation (i.e.: 1968 Brussels Convention), a wide array of preliminary rulings on its interpretation. Besides, the CJEU analysed the material scope and the active or passive standing of the parties to bring cross border actions before the Courts, by means of the assessment of the legal relationship given by the subject matter of the action.
} 
On the other hand, -as the merits of the case are related to $B 2 C$ unfair commercial practices and consumer law of the EU-, the CJEU analyses whether certain remedies set out in these consumer protection rules, -namely, the cease and desist orders (injunctive relief) as collective redress-, can be considered or not also within the material scope of the Brussels I bis Regulation and the interplay between all these acquis communautaire.

Keywords: civil and commercial matters; unfair commercial practices; Business to consumerB2C; unfair trading practice; Brussels I bis Regulation; locus standi; iure imperii; cease and desist orders (orders for the cessation); injunctions; penalty payments; consumer organizations/associations; collective interest; public authority; powers conferred by a legislative act; Directive 2005/29; Directive $2009 / 22$.

Sumario: I. Introducción: 1. Prácticas comerciales desleales $B 2 C$, prácticas de mercado y Reglamento Bruselas I bis: 2. Resumen de los hechos y de la cuestión prejudicial al Tribunal de Justicia de la Unión Europea; II. Las consideraciones de Derecho internacional privado; 1. Elementos para interpretar el concepto europeo "materia civil y mercantil” y el ámbito material del Reglamento Bruselas I bis; 2. Exclusión de los actos iure imperii del ámbito material del Reglamento Bruselas I bis; 3. Jurisprudencia anterior relacionada en relación con la tutela transfronteriza de los consumidores contra prácticas comerciales desleales $B 2 C$; 4 . La vinculación de la cuestión accesoria con la principal y la aplicación del Reglamento Bruselas I bis; III. Sobre el fondo del asunto: el Derecho derivado de prácticas comerciales desleales y de consumo. La tutela de los "intereses económicos colectivos"; 1 . El artículo 11 de la Directiva 2005/29 de prácticas comerciales desleales y la relación con la Directiva 2009/22; 2 . El significado de “intereses colectivos de los consumidores" en el Derecho derivado de protección a los consumidores y lucha contra las prácticas comerciales desleales $B 2 C$; IV. Conclusiones.

\section{Introducción}

\section{Prácticas comerciales desleales B2C, prácticas de mercado y Reglamento Bruselas I bis}

1. La STJUE Movic BV (C-73/19) suscita interés para el Derecho internacional privado europeo, en especial, al Derecho procesal civil internacional. La interpretación del TJUE en este caso gira en torno al concepto europeo "materia civil y mercantil", y el ámbito material del Reglamento Bruselas I $b i s^{2}$. Un concepto que ha producido numerosas cuestiones prejudiciales al TJUE en todos los instrumentos de DIPr patrimonial europeo relativos a la materia civil y mercantil. Siendo la jurisprudencia del TJUE relevante para interpretar este concepto. Uno de los motivos por los que debe atenderse a esta jurisprudencia es que este concepto no ha sido nunca desarrollado con precisión por estos instrumentos jurídicos. Solo definido por el legislador europeo ${ }^{3}$.

${ }^{1}$ STJUE (Sala Primera), Movic BV, de 16 de julio de 2020, C-73/19, (ECLI:EU:C:2020:568); Conclusiones del Abogado General Sr. Szpunar, de 23 de abril de 2020, C-73/19 (ECLI:EU:C:2020:297) J. I. PAREDES PÉrEz, "Ámbito material de aplicación del Reglamento Bruselas I bis y acciones colectivas de cesación ejercitadas por autoridades públicas en defensa del interés general de los consumidores (Sentencia del Tribunal de Justicia de 16 de julio de 2020, asunto C-73/19) (LA LEY 69263/2020 Movic BV y otros", Diario La Ley Unión Europea, n84, 2020; G. VAN CALSTER, "Enforcement of unfair trading practices and "civil and commercial". Szpunar AG extensively in Movic (reticket tours)", 28/04/2020, disponible en: https://gavclaw.com/tag/ acta-iure-imperii/; ID., "The CJEU in Movic on enforcement of unfair trading practices and the less than abstract determination of "civil and commercial", 15/07/2020, disponible en: https://gavclaw.com/2020/07/16/the-cjeu-in-movic-on-enforcement-ofunfair-trading-practices-and-the-less-than-abstract-determination-of-civil-and-commercial/; F. MéLLIN, "Réglement Bruxelles I bis : à propos de la notion de "matière civile et commerciele"', Dalloz actualité, 8 septiembre de 2020, disponible en: https:// www.dalloz-actualite.fr/flash/reglement-bruxelles-i-bis-propos-de-notion-de-matiere-civile-et-commerciale\#.X61OIS9Q2vM

${ }^{2}$ Reglamento (UE) No 1215/2012 del Parlamento europeo y del Consejo de 12 de diciembre de 2012 relativo a la competencia judicial, el reconocimiento y la ejecución de resoluciones judiciales en materia civil y mercantil, 20 de diciembre de 2012, DOUE, L 135/1.

${ }^{3}$ G. VAN CALSTER, "Enforcement of unfair trading practices and "civil and commercial". Szpunar AG extensively in Movic...", loc.cit. 
2. En este caso, la cuestión prejudicial nace con la interpretación de si las acciones transfronterizas colectivas de cesación (collective redress) establecidas en la Directiva 2009/224, -que pueden entablar las personas jurídicas que tengan la capacidad reconocida por la norma para tutelar los intereses colectivos de los consumidores (sean entidades de Derecho público o Derecho privado)-, tienen cabida o no en el ámbito material del Reglamento Bruselas I bis. ${ }^{5}$ La pregunta recuerda a la STJUE Henkel y jurisprudencia posterior, comparándose con la misma.

3. El Derecho derivado de prácticas comerciales desleales que se aplica al fondo de este asunto, puede considerarse no sólo como puro Derecho privado, sino que ha avanzado en el Derecho de la UE hacia la consideración de Derecho privado Institucional. A la luz de los intereses económicos que tutela, en concreto, cuando en la DPCD se incluye la tutela del buen funcionamiento del mercado interior, aparte de los intereses colectivos de los consumidores $B 2 C$ y de los competidores $B 2 B$ (estos últimos tutelados de forma indirecta mediante la tutela realizada a los consumidores) ${ }^{6}$. No todas sus normas son dispositivas para las partes o pueden considerarse Derecho dispositivo, característica principal del Derecho privado. Sus características actuales, le hacen ser parte de un cuerpo de normas que pertenecen a lo que se conoce como Derecho de mercado (Market Law). Siendo una de sus peculiaridades en el ámbito del Derecho privado europeo, los límites que tiene con el Derecho público en algunos de estos intereses que tutela y los medios de tutela que se pueden establecer para protegerlos ${ }^{7}$.

4. Este tratamiento como Derecho privado Institucional no está reconocido de forma expresa aún en el acervo de normas de la UE, ni en el Derecho de los Estados miembros. No obstante, se trae a colación por las razones que se explicarán en el epígrafe relativo a las cuestiones de fondo. Especialmente en la interpretación de "intereses colectivos/generales" de los consumidores y la interposición de determinado tipo de acciones procesales para prevenir las prácticas comerciales desleales de tipo $B 2 C$.

La complejidad en la interpretación de este acervo de normas en litigios con elemento extranjero reside en la debida conexión-relación que debe hacerse de todo el acquis communautaire del Derecho de consumo europeo, incluyendo la lucha contra las prácticas comerciales desleales con los instrumentos de DIPr patrimonial europeo ${ }^{8}$.

\section{Resumen de los hechos y de la cuestión prejudicial ante el Tribunal de Justicia de la Unión Europea}

5. En el año 2016, las autoridades belgas de protección de consumidores (Belgische Staat-Directeur Generaal van de Algemene Directie Economische Inspectie) citaron ante el juzgado de lo mercantil

${ }^{4}$ Directiva 2009/22/CE del Parlamento Europeo y del Consejo, de 23 de abril de 2009, relativa a las acciones de cesación en materia de protección de los intereses de los consumidores, $D O$ L 110, 2009, p. 30.

${ }^{5}$ STJUE Henkel, de 1 de octubre de 2002, C-167/00 (ECLI:EU:C:2002:555).

${ }^{6}$ Directiva 2005/29/CE del Parlamento Europeo y del Consejo, de 11 de mayo de 2005, relativa a las prácticas comerciales desleales de las empresas en sus relaciones con consumidores en el mercado interior, que modifica la Directiva 84/450/CEE del Consejo, las Directivas 97/7/CE, 98/27/CE y 2002/65/CE del Parlamento Europeo y del Consejo y el Reglamento (CE) No2006/2004 del Parlamento Europeo y del Consejo ("Directiva sobre las prácticas comerciales desleales"), 11 de Junio de 2005, OJ L 149, p. 22.

${ }^{7}$ Siendo por ello considerado en parte como Derecho económico, cuyos principios vectores nacen de los derechos fundamentales de las Constituciones económicas, como el derecho a la libre empresa; M. VIRGós Soriano, El comercio internacional en el nuevo Derecho español de la competencia desleal, Madrid, Civitas, 1992; F. Henning BodewIG, International Handbook on Unfair Competition Law, Beck, 2013; W. H.Boom, "Unfair Commercial Practices”, n C.TwIGG-FLeSner (ED.), Research Handbook on EU Consumer and Contract Law (Research Handbooks in European Law series), Cheltenham, 2016, pp. 388-405, esp. p. 399: “ (...) From this perspective, the UCP Directive is typical of the classical economic framework of EU consumer policy"; H. Collins, "The Unfair Commercial Practices Directive", ECLR, 2005, pp. 417 y ss; N. ReICH, Undertanding European Consumer Law, Intersentia, 2009; N. RZEPECKI, Droit de la consommation et théorie générale du contract, Université Aix Marseille, 2002; S. Weatherill, EU Consumer Law and Policy, 2aed., Elgar European Law, 2013, esp. pp. 92-143.

${ }^{8}$ Apoyándose en estas líneas, lo que se denomina el análisis holístico del Derecho, que analiza el todo para llegar a la suma completa de las partes; C.P. Pambouakis, "Droit international privé holistique: Droit Uniforme et droit international privé", Rec. Des C., t. 330. Martinus Nijhoff Publishers, 2007, pp. 27-447. 
(Rechtbank van koophandel Antwerpen-afdeling Antwerpen) en Amberes (Bélgica) en un procedimiento de medidas cautelares, a tres sociedades holandesas: Movic, Events Belgium y Leisure Tickets \& Activities international. Estas empresas operan en el mercado belga a través de sus páginas web atrayendo a consumidores belgas. La pretensión principal se sostenía en la demanda en que estas empresas habían estado revendiendo tiques de conciertos/espectáculos mediante sus páginas web a un precio superior al inicial de lo que costaban las entradas. Según el Derecho belga no se pueden revender entradas (resale tickets) a un precio superior del original de la misma.

Con ello, estas empresas estaban infringiendo la normativa belga, en particular la Ley de 30 de julio de 2013 y el Título IV, capítulo I, del Código de Derecho económico (Wetboek economisch recht) donde se transpusieron en la normativa belga las disposiciones relativas a la DPCD ${ }^{9}$. De otro lado, las acciones que se interponen por esta autoridad belga que representa a los consumidores y que tiene por misión también el mantenimiento de la lealtad en las relaciones de mercado, fueron varias. Entre ellas, la acción declarativa de deslealtad de este tipo de prácticas comerciales desleales $B 2 C$ así como las acciones colectivas de cesación en base a la Directiva 2009/22 relacionada con la DPCD en la tutela de intereses colectivos de los consumidore ${ }^{10}$. De forma accesoria a la cuestión principal, las autoridades belgas solicitaban una multa coercitiva contra dichas sociedades holandesas por cada infracción comprobada y la publicidad de la resolución pronunciada.

6. La representación procesal de las empresas holandesas plantea cuestión de incompetencia judicial internacional basándose en que las autoridades belgas de protección de consumidores actuaban revestidas de poder público. Ello hacía imposible la aplicación del Reglamento Bruselas I bis por tratarse de un acto iure imperii. El 25 de octubre del 2017, el juzgado de los mercantil de Amberes se declara incompetente fallando a favor de la excepción de incompetencia planteada por las demandadas, considerando que las acciones no se podían entender incluidas en la materia "civil y mercantil" a efectos del Reglamento Bruselas I bis.

7. Contra esta resolución, las autoridades belgas interponen resolución ante el Tribunal de Apelación de Amberes (hof van beroep te Antwerpen). Se debatía si el uso de atribuciones de una autoridad para ejercitar una acción con objeto de poner fin a las infracciones de la Ley de 30 de julio y del CDE es una potestad y ejercicio del poder público y que la actividad que realizan no afecta a las autoridades. No obstante, las autoridades belgas defendieron que estaban ejerciendo su poder para representar el interés colectivo de los consumidores frente a prácticas comerciales desleales $B 2 C$, porque así lo tenían otorgado por la normativa belga y el Derecho de la UE en la materia.

8. Ante esta circunstancia, el Tribunal de Apelación de Amberes decide suspender el procedimiento y plantear al TJUE especialmente la siguiente cuestión prejudicial; “¿Queda comprendida en la "materia civil y mercantil" en el sentido del artículo 1, apartado $1^{\circ}$ del Reglamento 1215/2012, un litigio relativo a una acción dirigida que se declare y se ordene la cesación de prácticas de mercado y/o prácticas comerciales infractoras frente a consumidores, ejercida por una autoridad belga (...) y puede

\footnotetext{
${ }^{9}$ Belgisch Staatbald de 6 de septiembre de 2013, prohíbe la reventa de entradas con carácter habitual, la exhibición de entradas para su reventa con carácter habitual y el suministro de medios que se utilicen para la reventa con carácter habitual. Aparte, la citada norma también prohíbe la reventa ocasional de entradas a un precio superior a su precio definitivo. A diferencia de la situación en España, donde la DPCD se transpone en la Ley de competencia desleal. Puede accederse al mismo en francés en la siguiente página web: http://www.ejustice.just.fgov.be/eli/loi/2013/02/28/2013A11134/justel ; sobre el tratamiento de estas acciones en Bélgica, S. VoEt, "Consumer Collective Redress in Belgium: Class Actions to the Rescue?, European Business Organization Law Review, Vol. 16, 2015, pp. 121-143.

${ }^{10}$ Conclusiones AG Sr Szpunar, STJUE Movic BV, p. 13, en relación con este particular considera que la autoridad remitente no explica de qué modo se relacionan entre sí, las prácticas comerciales desleales y las de mercado. Únicamente explican que la Ley 30 de julio de 2013 se debe considerar lex specialis frente al Código de Derecho económico. Pero que, no obstante, deduce el AG Sr Szpunar que ambos actos legislativos están orientados al mismo objetivo: la tutela de los intereses colectivos de los consumidores. El TJUE debe también proporcionar al tribunal remitente todos los elementos de interpretación del Derecho de la UE que puedan permitirle resolver el asunto que le ha sido sometido reformulando la cuestión prejudicial si es necesario; STJUE Movic BV, FD. 29-30.
} 
quedar comprendida, por tal motivo, en el ámbito de aplicación de dicho Reglamento una resolución judicial dictada en tal litigio?" ${ }^{11}$.

\section{Las consideraciones de Derecho internacional privado europeo}

\section{Elementos para interpretar el concepto europeo "materia civil y mercantil" y el ámbito material del Reglamento Bruselas I bis}

9. La STJUE responde, -atendiendo a lo anterior-, a si el litigio principal basado en acciones transfronterizas de cesación contra prácticas comerciales desleales $B 2 C$ y prácticas de mercado, tienen cabida en el ámbito material del Reglamento Bruselas I bis, i.e.: artículo 1 apartado $1^{012}$. Y deben considerarse como materia civil y mercantil según el mismo instrumento jurídico.

10. El concepto europeo "materia civil o mercantil" siendo un concepto "autónomo" de los instrumentos del DIPr patrimonial europeo, ha sido siempre controvertido ${ }^{13}$. Muchas materias que se entienden comprendidas en el Derecho civil patrimonial y / o Derecho privado que este instrumento y los de DIPr patrimonial europeo abarcan, no están todavía armonizadas en el Derecho derivado de la UE para los Estados miembros. Su interpretación, por tanto, debe ser acorde a los principios vectores de estos instrumentos de DIPr y del Derecho privado de los Estados miembros, garantizando la igualdad, coherencia e uniformidad de los derechos y obligaciones que emanan de todos ellos, así como los instrumentos de Derecho derivado que puedan considerarse como Derecho privado, como es el caso del Derecho de consumo europeo ${ }^{14}$, o Derecho privado Institucional, como es el caso del Derecho contra las prácticas comerciales desleales $B 2 C^{15}$.

11. Implica entonces que se deben hacer diferencias entre lo que debe entenderse cómo materia civil y la mercantil y lo que se considera para el Reglamento Bruselas I bis, -a efectos de poder calificar debidamente la pretensión de las partes-, como Derecho privado y / o público. Con independencia de cómo se observe en el Derecho sustantivo de los Estados miembros ${ }^{16}$. Esto a su vez comprende un

${ }^{11}$ Las demandadas, el Gobierno belga y la Comisión Europea presentaron observaciones escritas. La vista se celebró el 29 de enero de 2020 (Conclusiones AG Sr Szpunar, STJUE Movic BV., p. 11.)

${ }^{12}$ Vid. Cdo. 10 del Reglamento Bruselas I bis; STJUE Gradbenišco Korana, de 29 de febrero de 2019, C-579/17 (ECLI:EU:C:2019:162); G. VAN CALSTER, European Private International Law, Hart (Bloomsbury), 2017, pp. 23-24.

${ }^{13}$ C. TOAder, "La notion de matière civile et commerciale », en B. Hess, E. JAYME Y H.P. MANESEL (eds.), Europea als Rechtsund Lebensraum : Liber amicorum für Christian Kohler zum 75. Geberstag am 18 Juni 2018, Bielefeld, 2018, pp. 515-526.

${ }^{14}$ Por todos, H.-W. Micklitz, N. Reich y P. Rotт, Understanding European Consumer Law, Intersentia, 2009, considerando el Derecho de consumo europeo como la base de lo que puede considerarse el Derecho privado europeo; , K.J.CSERES, "Enforcing the Unfair Commercial Practices Directive: the Enforcement Model of the Netherlands", en T. Tотн, Unfair Commercial Practices: The Long Road to Harmonized Law Enforcement, Pazmany Press, 2014, pp. 19-36, las prácticas comerciales desleales son consideradas parte del acervo de normas de Derecho privado de todos los Estados miembros y del Derecho derivado de la UE y no infracciones administrativas objeto de Derecho público. Aunque pueda existir una relación entre la aplicación privada y pública de las mismas.

${ }^{15}$ G. VAN CAlster, "Enforcement of unfair trading practices ...”, loc.cit.; B.Hess, "The Private-Public Divide in International Dispute Resolution", Rec des C., vol. 388, The Hague, 2018; M. Weller, "Opinion of AG Szpunar on "civil and commercial matters" according to Article 1(1) Brussels I bis Regulation in Case C- 73/19-Movic", Conflict of Laws, 23 abril de 2020; ID. "ECJ on "civil and commercial matters" under Article 1 (1) Brussels I bis Regulation, judgment of 16 July 2020 , C-73/19-Movic", Conflict of Laws, 12 de agosto 2020, disponible en: https://conflictoflaws.net/2020/ecj-on-civil-and-commercial-matters-under-article-1-1-brussels-ibis-regulation-judgment-of-16-july-2020-c-73-19-movic/ ; sobre la coherencia en el DIPr patrimonial europeo y los problemas de interpretación, S. SÁNCHEZ LOREnZo, "El principio de coherencia en el Derecho internacional privado europeo", REDI, vol. 70, n² , julio diciembre 2018, pp. 17-47; J. I. PAREDES Pérez, “Ámbito material de aplicación del Reglamento Bruselas I bis y acciones colectivas de cesación ejercitadas por autoridades públicas en defensa del interés general de...", loc.cit.; Conclusiones AG Sr Szpunar, STJUE Movic BV FD. 41, la coherencia de la que habla en relación al Reglamento Roma II, cuando analizó la posición en la STJUE Henkel.

${ }^{16}$ STJUE Movic BV, FD. 33 (referencia a la reciente STJUE Rina, C-641/18 (EU:C:2020:349)); STJUE flyLAL Lithuanian Airlines, de 23 de octubre de 2014, C-302/13 (ECLI:EU:C:2014:2319), FD. 24; STJUE Fahnenbrock y otros c. República 
debate interesante que excede de las ideas que deben hacerse en este comentario, los límites entre el Derecho público y el Derecho privado y cómo el legislador europeo ha tenido en cuenta los principios del Derecho privado y público de los Estados miembros para la consecución de los instrumentos de DIPr patrimonial europeo que, de forma posterior, el TJUE interpreta para asegurar la coherencia y uniformidad en su aplicación práctica ante las autoridades y tribunales de los Estados miembros ${ }^{17}$.

12. El TJUE lo ha ido interpretando de forma amplia en su jurisprudencia y en este asunto lo ha vuelto a poner de relieve ${ }^{18}$. Para saber si una materia está comprendida en su ámbito material y no está excluida de aquellas que considera como Derecho público, hay que atender especialmente a dos elementos; (i) la naturaleza de los derechos cuya salvaguardia garantiza el Reglamento Bruselas I bis (objeto del litigio), (ii) y la relación jurídica entre las partes ${ }^{19}$. Con carácter alternativo, a los fundamentos y modalidades de ejercicio de la acción entablada (dados por el Derecho procesal de cada Estado miembro o el Derecho derivado de la UE $)^{20}$.

13. Si la naturaleza de la acción está ligada al ejercicio del poder público, entonces se entenderá excluida del ámbito material del Reglamento Bruselas I bis, como se analiza en el siguiente apartado.

\section{Exclusión de los actos iure imperii del ámbito material del Reglamento Bruselas I bis}

14. Después de analizar la naturaleza del litigio y su objeto hay que atender al segundo elemento para poder caracterizar el litigio como "materia civil y mercantil" en el Reglamento Bruselas I bis. El segundo elemento es la naturaleza jurídica de la relación entre las partes. Para poder determinar si en casos como éste, quien ostenta la legitimidad activa siendo una entidad de carácter público, lo ha hecho ligada al ejercicio del poder público. Pudiendo entenderse que, de ser así, es un acto iure imperii, que no está incluidos en el ámbito material del Reglamento Bruselas I bis ${ }^{21}$.

15. Como recuerda el TJUE y la Doctrina, el acto iure imperii requiere que la autoridad actúe en su función pública representando al Estado. Esto es, si la potestad otorgada a la autoridad está otorgada por normas de Derecho público o no. O que también podría haber sido otorgada a una entidad de Derecho privado (prerrogativas que particulares no pueden utilizar en igualdad de condiciones frente a la entidad pública $)^{22}$.

Helénica, de 11 de junio de 2015, C-226/13, C-245/13, C-247/13 (ECLI:EU:C:2015:383), FD. 34; STJUE Pula Parking, de 9 de marzo de 2017, C-551/15 (ECLI:EU:C:2017:193); en la Doctrina: Ibid (VAn CAlster), pp. 23-24; A.L.Calvo Caravaca y J. Carrascosa GonzÁlez, Derecho internacional privado, vol. 1, 16 ed., Comares, 2016, pp. 210-212

${ }^{17}$ Vid.supra Epígrafe I.2; M. WelleR, “Opinion of...”, loc.cit.; Conclusiones AG Sr Szpunar STJUE Movic BV, en relación a la STJUE Verein für Konsumenteninformation c. Amazon EU Sarl, de 28 de julio de 2016, C-191-15 (ECLI:EU:C:2016:612); J. I. PARedes Pérez, “Ámbito material de aplicación del Reglamento Bruselas I bis y acciones colectivas de cesación ejercitadas por autoridades públicas en defensa del interés general...", loc.cit.

${ }^{18}$ STJUE Movic BV FD. 34; A.L.Calvo Caravaca y J. Carrascosa González, Derecho internacional.., vol. 1, op.cit., p. 211 y p. 217, el TJUE ha interpretado de forma amplia el concepto materia civil y mercantil y de forma estricta que debe entenderse como excluido del concepto (por tanto del ámbito material del Reglamento Bruselas I bis).

${ }^{19}$ A.L.Calvo Caravaca y J. Carrascosa GonzÁlez, Derecho internacional..., vol. 1, op.cit., p. 211, no siendo relevante tal como dicen los autores, -tras su análisis de la jurisprudencia del TJUE en la materia-, la naturaleza de la materia o procedimiento judicial.

${ }^{20}$ Infra I.2; Ibid (VAN CALSTER), pp. 23-24; STJUE Movic BV FD. 37.

${ }^{21}$ STJUE Ruffer, de 16 de diciembre de 1980, C-814/79 o más reciente la STJUE Fahnenbrock y otros, FD. 7 y 8 (ECli:EU:C:1980:291); A.L.Calvo Caravaca y J. Carrascosa González, Derecho internacional... (vol.1), op.cit., p. 214 ; P. Rogerson, “Article 1" en U. Magnus y P. Mankowski (Eds.), Brussels I Regulation (2 ${ }^{\text {nd }}$ Revised Edition), Commentaries on Private International Law, Sellier, 2012, pp. 47-75, esp. pp.54-55.

${ }^{22}$ G. VAN CALSTER, "Enforcement of unfair trading practices...", loc.cit.; STJUE Sunico, 12 de septiembre de 2013, C-49/12 (ECli:EU:C:2013:545); A.L.Calvo Caravaca y J. Carrascosa González, Derecho internacional... (vol.1), op.cit., p. 155; R. ARENAS Garcia, "Ámbito material de aplicación del Reglamento 44/2001 y deudas fiscales. Comentario a la STJUE (Sala Tercera) de 12 de septiembre de 2013, Asunto C-49/2012, “The Commissioners of Her Majesty's Revenue \& Customsy Sunico ApSm M \& B Holdings ApS, Sunil Kumar Harwani”, Deloitte-CISS, Diciembre 2013, pp. 40-58. 
16. Desde la STJUE Eurocontrol, el TJUE estableció que el Reglamento I bis se aplica a los litigios entre las autoridades y los particulares, cuando éstas no actúan en su capacidad de representación del Estado, y las facultades que les has sido otorgadas no representan el ejercicio del poder público ${ }^{23}$. En estos supuestos, además, la autoridad no es la demandada que tenga que alegar su inmunidad de jurisdicción ${ }^{24}$.

En la STJUE Pula Parking, el TJUE ya puso de relieve este aspecto. El hecho que se deleguen ciertas facultades a una autoridad no significa que dicha autoridad ejerza prerrogativas de poder público (y que sus poderes sean exorbitantes frente a los particulares). Aparte, el AG Sr Szpunar recuerda que la interpretación sobre "prerrogativa de poder público" se tiene que hacer acorde a lo establecido por la jurisprudencia del TJUE en la interpretación del ámbito material del Reglamento Bruselas I bis. Una forma más de volver a recordar que es un concepto europeo que hay que interpretar de forma uniforme en casos análogos.

A sensu contrario, en la STJUE Kuhn, el TJUE habiendo examinado la relación entre el particular y la autoridad del Estado miembro en cuestión, consideró que siendo lo importante la posición del Estado frente al particular, si existía prerrogativa de poder público ${ }^{25}$.

17. En el asunto Movic $B V$, la autoridad no está actuando en representación del Estado, sino en calidad de organización que tutela intereses de los consumidores, porque así tiene otorgada esta facultad por la norma belga. La misma facultad y ejercicio podría haberse otorgado a una entidad de Derecho privado, en las mismas condiciones. La norma del Derecho derivado en cuestión, -como se explicará en el epígrafe III-, otorgó a cada Estado miembro la facultad de legitimar a entidades de Derecho público o privado para la tutela de los consumidores por igual ${ }^{26}$. Estas prerrogativas son las mismas que se otorgan a las organizaciones de protección de los consumidores de carácter privado legitimados para la defensa de los consumidores. No se están haciendo reservas a las autoridades belgas mediante privilegios. Por ello, la posición procesal que ostentan frente a los profesionales la misma. No hay desequilibrio procesal en su relación jurídica, entre la de las autoridades que tutelan los intereses colectivos de los consumidores y las empresas demandadas del otro Estado miembro. Siendo determinante para poder valorar que finalmente puedan entenderse comprendidas este tipo de acciones transfronterizas en el ámbito material del Reglamento Bruselas I bis.

18. Tampoco en como la autoridad belga de protección a los consumidores obtuvo las pruebas que aportó en el litigio, que se basaban en reclamaciones de consumidores que le llegaban por ser la que debe recibirlas. De nuevo, si hubiera sido una entidad de Derecho privado también le hubiesen llegado dichas reclamaciones de la misma forma, para aportarlos en el litigio principal. De ahí que el AG Sr Szpunar lo compare con la respuesta ofrecida por el TJUE en la STJUE Sunico. El hecho que hayan obtenido pruebas gracias a sus prerrogativas de poder público no tiene que afectar a la relación jurídica entre las partes ni al objeto o naturaleza jurídica del litigio que sigue siendo Derecho privado ${ }^{27}$.

El TJUE y el AG Sr Szpunar lo ponen de relieve cuando reconocen que una acción que haya sido ejercitada por una autoridad no puede quedar excluida del ámbito de aplicación del Reglamento

${ }^{23}$ STJUE LTU c. Eurocontrol (Lechouritou), de 14 de octubre de 1976, C-29/76 (ECLI:EU:C:1976:137). Otros asuntos posteriores y de la misma relevancia que Eurocontrol en la interpretación de actos iure imperii y Convenio de Bruselas son: STJUE Ruffer, de 16 de diciembre de 1980, C-814/79 o más reciente la STJUE Fahnenbrock y otros, p. 7 y 8; STJUE Hellenische Republik c. L. Kuhn, 15 de noviembre de 2015, C-308/17 (ECLI:EU:C:2018:911); STJUE Baten, de 14 de noviembre de 2002, C-271/00 (ECLI:EU:C:2002:656)

${ }^{24}$ A.L.Calvo Caravaca y J. Carrascosa González, Derecho internacional... (vol.1), op.cit., p. 155; R. Arenas GARCIA, "Ámbito material de aplicación del Reglamento 44/2001 y deudas fiscales. Comentario a la STJUE (Sala Tercera) ...”, loc.cit.; P. Rogerson, “Article ..”, loc.cit., en U. Magnus y P. Mankowski (Eds.), Brussels I Regulation ..., op.cit.

${ }^{25}$ Conclusions AG Sr Szpunar, STJUE Movic BV p. 34 in fine. El elemento decisivo dice el AG es que estas disposiciones no coloquen a la autoridad en situaciones jurídicas en las que no se aplica el Derecho común (mediante una remisión a las normas de Derecho civil).

${ }^{26}$ STJUE Movic BV, FD. 52; infra Epígrafe III.1; Ibid (Calvo Caravaca / Carrascosa GonzÁlez, pp. 214-215).

${ }^{27}$ Conclusiones AG Sr Szpunar STJUE Movic BV, ptos. 49-62. Los medios de impugnación de estos documentos se hacen de conformidad con el Derecho procesal de cada Estado miembro, que podrá proporcionar diferentes medios en función de quién aporte los documentos. 
Bruselas I bis sólo porque dicha autoridad haya hecho uso de medios de prueba obtenidos gracias a sus prerrogativas, porque debilitaría la eficacia práctica de los medios de ejecución de las normas de protección de los consumidores reconocidos por el legislador de la UE (v.gr.: lo establecido en el Considerando 21 de la DPCD).

\section{Jurisprudencia anterior en relación con la tutela transfronteriza de los consumidores contra prácticas comerciales desleales $B 2 C$}

19. Estimar que estas acciones transfronterizas están excluidas del Reglamento Bruselas I bis $^{28}$, puede reducir el papel de las autoridades, aun cuando estos procedimientos apenas puedan distinguirse de los que promueven las personas de Derecho privado ${ }^{29}$.

De hecho, en materia de acciones de cesación colectivas, según la normativa belga, las autoridades están exentas de demostrar que representan un interés o derecho propio. En el asunto Movic BV, queda entonces demostrado con ello, que la actividad que realiza la autoridad de defensa de los intereses colectivos de los consumidores es equiparable a la que tienen otorgadas en otros Estados miembros (por la misma normativa de Derecho derivado) a asociaciones en defensa de los consumidores de tipo privado, sin tener por ello, ningún interés propio.

20. Puede compararse, como se puso de relieve en la introducción con la respuesta del TJUE en la STJUE Henkel. En este asunto también se preguntó el TJUE (aunque bajo el régimen anterior) si estaba comprendido en su ámbito material, las acciones ejercitadas por una autoridad (Verein für Konsumenteninformation) contra la inclusión de cláusulas abusivas en contratos $B 2 C$, de acuerdo con la Directiva $93 / 13^{30}$. El asunto Movic $B V$ se basa en acciones de cesación contra prácticas comerciales desleales $B 2 C$, de acuerdo con lo establecido en la DPCD y a la Directiva 2009/22, pero que se pueden igualmente entender comprendidas en el concepto "materia civil y mercantil" del Reglamento Bruselas I $b i s^{31}$, como considera el TJUE. La justificación se encuentra en que las acciones que tutelan a los consumidores comprendidas en este acervo de normas son consideradas Derecho privado. Se entiende que la reventa de tickets a un precio superior es una práctica comercial desleal $B 2 C$ y que la DPCD, como la Directiva 93/13 son Directivas que habilitan a las autoridades de los Estados miembros a perseguir prácticas contrarias a la buena fe que puedan ser reputadas como desleales, tanto en el Derecho de contratos de consumo como en otro tipo de relaciones entre los consumidores y los profesionales ${ }^{32}$.

\section{La vinculación de la cuestión accesoria y la principal y la aplicación del Reglamento Bruselas I bis}

21. Otro aspecto relevante de este asunto pero que no se termina de interpretar por el TJUE aunque sí por el AG Sr Szpunar ${ }^{33}$, fue la naturaleza de la multa coercitiva, cuestión accesoria a la princi$\mathrm{pal}^{34}$. La única pretensión que considera el AG Sr Szpunar que puede estar excluida del ámbito material del Reglamento Bruselas I bis es precisamente esta, que sí tiene relación con una prerrogativa de poder

\footnotetext{
${ }^{28}$ Infra Epigrafe III; Conclusiones AG Sr Szpunar STJUE Movic BV, p. 38: “(...) por lo menos en lo que se refiere al WER, que transpone la Directive 2005/29, la acción de cesación puede entablarse con personalidad jurídica, y en ciertas condiciones, por asociaciones en defensa de los intereses de los consumidores. Una asociación de esta índole no defiende intereses o derechos propios. Más bien, actúa en defensa de los intereses colectivos de los consumidores (...)".

${ }^{29}$ Conclusiones AG Sr Szpunar STJUE Movic BV, p. 44

${ }^{30} \mathrm{C}$. KeSSEDJIAN, "L'action en justice des associations de consommateurs et d'autres representatives d'interests collectifs en Europe ", Rivista di diritto internationale e processuale, n², 1997, pp. 281-ss ; P. JIMÉNEZ BLANCO, "El tratamiento de las acciones colectivas en materia de consumidores en el Convenio de Bruselas (1)”, Diario La Ley n5709, Unión Europea, 2003.

${ }^{31}$ Conclusiones AG Sr Szpunar STJUE Movic BV, p. 29 y p. 31 y 41.

${ }^{32}$ Artículo 3 apartado $2^{\circ}$ de la DPCD establece que la DPCD se aplica sin perjuicio del Derecho contractual de consumo.

${ }^{33}$ STJUE Movic BV, FD. 29 y 62.

${ }^{34}$ WeLLER, “Opinion of...", loc.cit
} 
público que no tienen atribuía las personas de Derecho privado en el supuesto que hubieran sido las legitimadas para accionar la tutela de los consumidores en Bélgica.

Se destaca sólo por el TJUE, que el hecho que una de las pretensiones accesorias o varias no se encuentren contenidas en el ámbito material del Reglamento Bruselas I bis, no significa que la cuestión principal e incluso otras cuestiones accesorias, no lo estén. Por ende, sigue entendiendo comprendidas las acciones transfronterizas de cesación en su ámbito material.

\section{Sobre el fondo del asunto: el Derecho derivado de prácticas comerciales desleales y de consu- mo. La tutela de los "intereses colectivos" de los consumidores}

\section{El artículo 11 de la Directiva de Prácticas comerciales desleales y la relación con la Directiva 2009/22}

22. La DPCD es una Directiva de corte general, y armonización "de máximos" que debe complementar a otras Directivas que también tutelan al consumidor, pertenecientes al conocido Fitness Check, en lo que esta Directiva no hayan contemplado en su ámbito material ${ }^{35}$. Todas ellas, tienen un objetivo "común" principal: la tutela de los intereses colectivos de tipo económico de los consumidores en sus relaciones frente a los comerciantes o profesionales en el mercado interior europeo.

Así, por ejemplo, se establece en el Anexo I de la Directiva 2009/22. Tanto la DPCD como la Directiva de cláusulas abusivas (Directiva 93/13) están destinadas a tutelar los intereses colectivos de los consumidores ${ }^{36}$. El artículo 3 apartado $4^{\circ}$ establece la compatibilidad de la DPCD como instrumento general frente a los de corte sectorial en la tutela de consumidores, como es la Directiva 2009/22. Explica a su vez en la primera cláusula general lo que debe considerarse como intereses económicos de los consumidores, que nada tienen que ver con los intereses del Estado, como tal.

23. En su artículo 11 apartado $1^{\circ}$ letras a y b, la DPCD concedió la facultad a los Estados miembros de establecer remedios fundamentalmente de tipo procesal para actuar en contra de las prácticas comerciales desleales $B 2 C$, y someterlas a un órgano administrativo competente para resolver reclamaciones o para entablar acciones judiciales pertinentes ${ }^{37}$. Por lo que cada Estado miembro en este aspecto, tuvo plena libertad para elegir quiénes eran estas autoridades o entidades y tribunales administrativos y otorgarles la capacidad de ordenar el cese de las prácticas y o emprender acciones legales, o prohibirlas. No se especificaba cómo tenían que hacerlo ${ }^{38}$. Su apartado $2^{\circ}$ concede a los Estados miembros que otorguen a estas autoridades ciertas facultades para perseguir las prácticas comerciales desleales $B 2 C$.

${ }^{35}$ Vid. Art. 1 DPCD y esp, Cdos. 10, 11 y 12; por ejemplo, Comisión Europea, “Comunicación al Palameno Europeo, al Consejo y al Comité Económico y Social Europeo: sobre la aplicación relativa a las practices comerciales desleaeles. Lograr un alto nivel de protección de los consumidores. Crear confianza en el mercado único", COM (2013) 138 final; EuropEAn CoMmISSION, "Commission Notice on the application of EU food and consumer protection law to issues of Dual Quality of ProductsThe specific case of food" C/ 327/01, de 29 Abril 2017, p. 2: "the Unfair Commercial Practices Directive, which ensures that consumers are not misled or exposed to aggressive marketing and that any claim made by traders in the UE is clear, accurate and sustained. It seeks to enable consumers to make informed and meaningful choices. This horizontal Directive applies to many commercial practices which are also regulated by other general or sector-specific EU legislation, such as food, toys, cosmetics, detergents and others, but only for those aspects which are not covered by sector legislation"; W. H.Boom, "Unfair Commercial...", loc.cit., en C.TWIGG-FLESNER (ED.), Research Handbook ..., op.cit.

${ }^{36}$ STJUE Movic BV, FD. 5.

${ }^{37}$ Cdo. 21 DPCD; De hecho, el artículo 11 concede mucho margen a los Estados miembros. A pesar que la DPCD es una Directiva de armonización de máximos, para establecer las medidas procesales oportunas. Siempre y cuando se establecieran de conformidad con lo establecido en la misma disposición, inter alia, K.J.CsERES, "Enforcing the Unfair Commercial Practices Directive: the enforcement model ...", loc.cit. en T. Тотн, Unfair Commercial Practices: The Long Road to Harmonized ... op.cit., pp. 19-36, esp. p. 23: "With regard to enforcement Article 11 of the UCPD leaves much discretion to the Member States in accordance with the principle of national procedural autonomy".

${ }^{38}$ Conclusiones AG Sr Szpunar STJUE Movic BV, p. 44. Con esto, el legislador de la UE, lo que hace es establecer un modelo de ejecución de la protección de los consumidores en el que los órganos administrativos no son competentes para conocer de las acciones contra las prácticas comerciales desleales, pero si para actuar ante los órganos jurisdiccionales nacionales 
Como, por ejemplo, el establecimiento de acciones de cesación, y de acciones de prohibición contra estas prácticas comerciales desleales $B 2 C$.

24. La Directiva 2009/22 se promulgó por el legislador europeo para armonizar un régimen de acciones colectivas de cesación colectivas en el mercado interior europeo para la tutela de los consumidores. Complemento a la DPCD, en cuanto como se ha manifestado en el párrafo anterior, la DPCD no armonizaba las cuestiones relativas al Derecho procesal, sólo abría la posibilidad de otorgar la tutela debida frente a las prácticas comerciales desleales $B 2 C$ que contempla su articulado ${ }^{39}$.

\section{El significado de "intereses colectivos de los consumidores" en el Derecho derivado de protec- ción a los consumidores y lucha contra las prácticas comerciales desleales B2C}

25. Para concluir. En el asunto Movic $B V$, las demandantes alegaban que la tutela concedida por la norma a la entidad de Derecho público no justificaba su acción, porque entienden que tutela los intereses públicos y no de los particulares actuando en una posición procesal diferente.

26. Ahora bien, lo que vienen a decir la Directiva 2009/22 y la DPCD como "intereses generales", no debe entenderse como la defensa y ejercicio de poderes públicos para tutelar "intereses públicos" (i.e.: del Estado), sino de los particulares (consumidores). El mismo Considerando $3^{\circ}$ de la Directiva 2009/22 explica que debe entenderse por "intereses colectivos", los intereses que no son "individuales". Es decir, los intereses que no pertenecen de forma separada a los particulares sino en colectividad, porque la lucha contra las prácticas comerciales desleales incluye la protección contra todos los intereses en el mercado: los de los consumidores $(B 2 C)$, los de los profesionales $(B 2 B)$ y los del mercado en general y su buen funcionamiento ${ }^{40}$.

27. Son estos los aspectos que merecen una mención. En ellos reside la complejidad de este acervo de normas que puede ser considerado como Derecho híbrido (a caballo entre el Derecho público y el Derecho privado). Como ya se ha reiterado. A diferencia de como sucede en el ámbito del Derecho de libre competencia europeo, no existe una aplicación pública en el Derecho derivado para el Derecho de prácticas comerciales desleales todavía, pero si que es cierto que las autoridades encargadas del control del Derecho de la libre competencia, ante ciertas prácticas comerciales desleales $B 2 C$ pueden actuar $^{41}$. Precisamente, en las que atentan contra el buen funcionamiento del mercado. No aquellas que tutelan, aunque sea de forma colectiva, los intereses de los otros participantes del mercado. Por ello, el TJUE considera que estas acciones transfronterizas de cesación en defensa de estos intereses $B 2 C$, deben ser considerados como "materia civil y mercantil". A la luz de todo lo analizado.

en defensa del interés de los consumidores, que los coloca en igualdad de condiciones con las personas u organizaciones del artículo 11 , apartado $1^{\circ}$, DPCD.

${ }^{39}$ Un análisis exhausto de las acciones colectivas de cesación y la Directiva 2009/22 así como la incidencia en el ámbito del DIPr europeo, A. PAто, Jurisdiction and Cross Border Collective Redress: A European Private International Law Perspective, Hart, 2019, pp. 45 y ss; L. CARballo Pineiro, Las acciones colectivas y su eficacia extraterritorial (Problemas de recepción y transplante de las "class action" en España), Servicio de publicaciones de Intercambio científico, vol.12 2009; I. ONANDIA CAÑAS, "La acción colectiva en la Unión Europea: ¿es posible encajarla en el Reglamento Bruselas I bis?", RJUAM, n³9, 2019, pp. 297-321; Z. TANZ, "Consumer Collective Redress in European Private International Law”, JPIL, vol.7, n 1, 2011, pp. 101-147; M.Danov, "The Brussels I Regulation: Cross-Border Collective Redress Proceedings and Jugdements", JPIL, vol.6, n², 2010, pp.359-393; Wv Bоом y M. Loos (EDs.), Collective Enforcement of Consumer Law-Securing Compliance in Europe through Private Group Action and Public Authority Intervention, Europa Law Publishing, 2007.

40 A. Рato, Jurisdiction and Cross Border Collective Redress..., op.cit., p. 76, teniendo en cuenta también que el Considerando $7^{\circ}$ de la Directiva 2009/22 establece que se aplicará sin perjuicio de las normas del DIPr. El artículo 3 apartado $7^{\circ}$ de la DPCD también establece que se aplicará sin perjuicio especialmente de las normas que determinan la competencia de los tribunales.

${ }^{41}$ Póngase de ejemplo, el artículo 3 de la Ley 15/2007, de 3 de julio, de Defensa de la Competencia, $B O E$, nº 159 , de 4 de julio de 2007. 


\section{Conclusiones}

28. Primera. Sobre el concepto europeo "materia civil y mercantil" del Reglamento Bruselas I bis .-Según esta STJUE se desprende que el TJUE se sigue reiterando en ofrecer una interpretación amplia del concepto "materia civil y mercantil" del Reglamento Bruselas I bis. Y una interpretación más estricta de lo que no debe considerarse como "materia civil y mercantil". Los elementos para interpretar el concepto europeo "materia civil y mercantil" son los siguientes: (i) naturaleza de la acción-objeto del litigio; (ii) relación entre las partes y, (iii) si la autoridad que interpone la acción está actuando en función de una prerrogativa o no (para valorar si puede ser considerado como un acto iure imperii).

El ámbito material de este instrumento jurídico debe comprender entonces aquellas acciones de cesación relativas a la tutela transfronteriza de los consumidores contra las prácticas comerciales desleales $B 2 C$ con independencia de si fueron interpuestas por una autoridad que tiene reconocido por la norma sustantiva esta facultad de representación de los intereses colectivos de los consumidores, o una entidad de Derecho privado que actuaría de la misma forma con las mismas prerrogativas concedidas. Siempre que se muestre que se encuentra en igualdad de condiciones procesales que las entidades de Derecho privado que demanda.

29. Segunda.- Sobre la aplicación de las acciones de cesación transfronterizas y protección de consumidores.- La materia que aborda el litigio principal es una materia de Derecho privado, al menos así está considerado en el Derecho derivado de la UE. Por ende, no puede entenderse que, aunque la Directiva 2009/22 otorgue la capacidad a las autoridades para ejercer acciones colectivas (colective redress) para tutelar a los consumidores en sus relaciones $B 2 C$ contra prácticas comerciales desleales, o prácticas de mercado contrarias a la buena fe, es materia de Derecho público. Incluso en su consideración de Derecho privado Institucional sigue siendo materia de Derecho privado en la mayor parte de los Estados miembros. Y como se observa también para los instrumentos de DIPr patrimonial europeo, como el Reglamento Bruselas I bis. Reforzando de esta forma la tutela transfronteriza a los consumidores contra las prácticas comerciales desleales $B 2 C$.

30. Tercera.-Intereses colectivos no son intereses públicos o representación del Estado.- Al hilo de lo anterior, este acervo de normas lo que tutela son intereses económicos colectivos de particulares, no los del Estado. Intereses privados. Al menos, en la tutela y observancia de como deben desarrollarse las relaciones $B 2 C$, y $B 2 C$ en el mercado. No en lo que se entiende por el tercer interés tutelado: el buen funcionamiento del mercado (interés general). Pero en este asunto, los intereses públicos no fueron puestos de relieve. Por ende, el TJUE no entró a valorarlo de forma más exhausta. 